Portland State University

PDXScholar

6-7-1996

\title{
Gender Differences in the Language Development of Late-talking Toddlers at Age 3
}

Nancy Ann Johnson

Portland State University

Follow this and additional works at: https://pdxscholar.library.pdx.edu/open_access_etds

Part of the Speech and Rhetorical Studies Commons

Let us know how access to this document benefits you.

\section{Recommended Citation}

Johnson, Nancy Ann, "Gender Differences in the Language Development of Late-talking Toddlers at Age 3" (1996). Dissertations and Theses. Paper 5253.

https://doi.org/10.15760/etd.7126

This Thesis is brought to you for free and open access. It has been accepted for inclusion in Dissertations and Theses by an authorized administrator of PDXScholar. Please contact us if we can make this document more accessible: pdxscholar@pdx.edu. 
The abstract and thesis of Nancy Ann Johnson for the Master of Science in Speech Communication: Speech and Hearing Sciences were presented June 7, 1996, and accepted by the thesis committee and the department.

COMMITTEE APPROVALS:

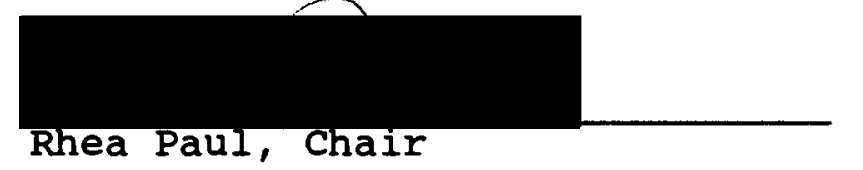

DEPARTMENT APPROVAL:

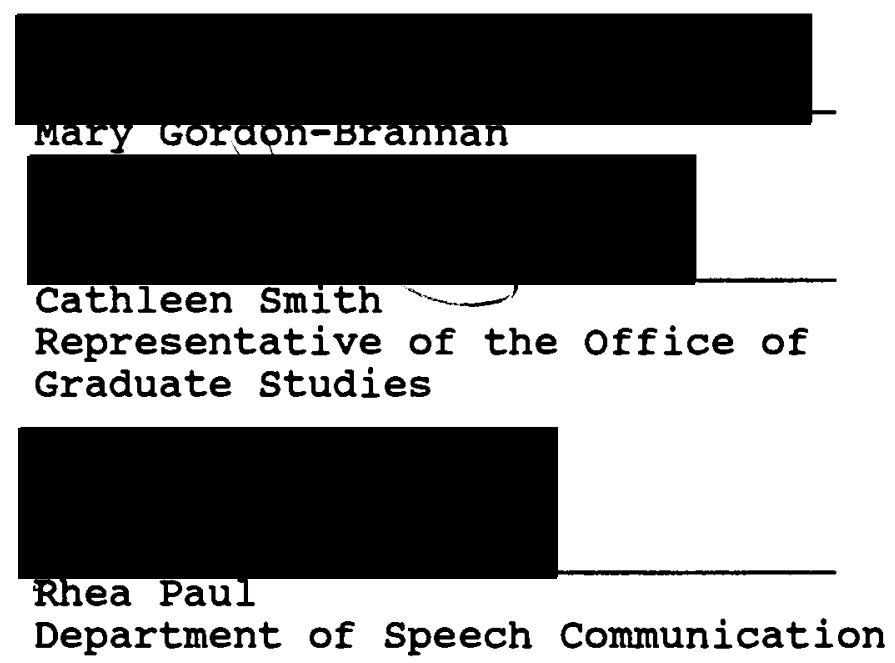

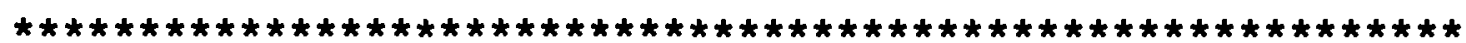

ACCEPTED FOR PORTLAND STATE UNIVERSITY BY THE LIBRARY

by on

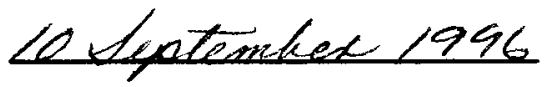




\begin{abstract}
An abstract of the thesis of Nancy Ann Johnson for the Master of Science in Speech Communication: Speech and Hearing Sciences presented June 7, 1996.
\end{abstract}

Title: Gender Differences in the Language Development of Late-Talking Toddlers at Age 3 .

Language is a major part of a child's early developmental growth. Research examining early language shows a wide variation in the rate of language acquisition and its pattern of development. These variations also exist when language development is delayed.

The purpose of this study was to investigate the possibility of a relationship between gender and language delay by looking for significant differences in the language skills of 3-year-old boys and girls who were identified as late-talkers (LTs) at the age of 2 .

Data used for analysis in this study were retrieved from data collected earlier as part of the Portland Language Development Project (PLDP) and a concurring study of late-talking girls. Subjects for this study were drawn from these larger cohorts. The files of all prospective subjects were examined for an expressive vocabulary of 
less than 50 words at 20-34 months, and for participation in the follow-up evaluation at age 3. Final selection of subjects for this study included 23 boys and 16 girls.

Scores from five previously administered assessment measures were compiled for analysis, including the Developmental Sentence score (DSS), the Expressive oneWord Picture Vocabulary Test (EOWPVT), the Goldman-Fristoe Test of Articulation (GFTA), the Test of Auditory Comprehension of Language-Revised (TACL-R), and the Peabody Picture Vocabulary Test-Revised. These measures were administered as part of the PLDP and the study of late-talking girls.

Mean scores for the boys and the girls were computed for each assessment measure. A two-tailed t-test was used to analyze the differences between these mean scores. The results revealed a significant difference, beyond the .05 level of confidence, between the boys' and girls' scores for the EOWPVT. Although no other significant differences were found, it was noted that the boys' scores were consistently higher than the girls' scores on all measures. It was also noted that, on 4 out of 5 assessment measures, a higher percentage of girls did not respond or could not complete the test due to inability to attend. The fifth measure, the PPVT-R, was completed by all subjects. 


\title{
GENDER DIFFERENCES IN THE LANGUAGE DEVELOPMENT OF LATE-TALKING TODDLERS AT AGE 3
}

by

NANCY ANN JOHNSON

A thesis submitted in partial fulfillment of the requirements for the degree of

\author{
MASTER OF SCIENCE \\ in \\ SPEECH COMMUNICATION: \\ SPEECH AND HEARING SCIENCES
}

Portland State University

1996 


\section{ACKNOWLEDGEMENTS}

I wish to extend sincere thanks to the members of my thesis committee, Dr. Rhea Paul, for providing support and guidance throughout this project, for sharing her infinite knowledge, and for allowing me to use her data, and Dr. Mary Gordon-Brannan and Cathleen Smith for their scrupulous editing and insightful suggestions.

Special thanks go to my daughter, Lindsey, and to my husband, Doug, who spent many, many afternoons, evenings, and weekends without their wife and mother, and who were constant reminders that there is life after graduate school. 
TABLE OF CONTENTS

PAGE

ACKNOWLEDGEMENTS . . . . . . . . . . . . . . . . ii

LIST OF TABLES • . • . . . . . . . . . . . . . v CHAPTER

I INTRODUCTION . . . . . . . . . . . . . 1

Statement of Purpose . . . . . . . . . 3

II REVIEW OF THE LITERATURE • . . . . . • . . . 4

Gender Differences in Normal

Language Development . . . . . . . 4

Possible Explanations for the Differences

The Role of Maternal Linguist Input

Gender Differences and Language Delay . . . 11

The Role of Maternal Linguist Input

Outcomes of Early Language Delay

Gender Differences and Language Related

Disorders . . . . . . . . . . 15

Learning Disabilities

Reading Disorders

summary . . • . . . . . . . . . . 19

III METHODS AND PROCEDURES . . . . . . . . 22

Subjects . . . . . . . . . . . . . 22

Selection of Subjects for the

Present Study

Subject Recruitment for the PLDP and Girls study

Description of subjects for the Present study 
Instrumentation for the Present Study . . 24

Developmental sentence score

Goldman-Fristoe Test of Articulation

Test for Auditory Comprehension of

Language-Revised

Expressive One-Word Picture

Vocabulary Test

Peabody Picture Vocabulary

Test-Revised

PLDP Reliability . . . . . . . . . . 34

Data Analysis . . . . . . . . . 35

IV RESULTS AND DISCUSSION • • • • • • • • • • • 37

Results . . . . . . . . . . . 37

Discussion . . . . . . . . . . 39

V SUMMARY AND IMPLICATIONS . . . . . . . . . . 42

Summary • . . . . . . . . . . . . . . . 42

Implications . . . . . . . . . . . 44 4

Clinical

Research

REFERENCES

48

APPENDICES

A HUMAN SUBJECTS RESEARCH WAIVER • • . • • • 55

B LANGUAGE DEVELOPMENT SURVEY . • . • . . . . 57

C RAW DATA FOR THE TWO GROUPS OF

SUBJECTS AT INTAKE AND 3-YEAR

EVALUATION 


\section{LIST OF TABLES}

\section{TABLE}

PAGE

1 Demographic Means and Standard Deviations for Subjects Used in this Study . . . . . 25

2 Standardized Measures Used for Comparison in this study... . . . . . . . . . 28

3 Interrater Reliability for the PLDP . . . . 34

4 Types of Scores Used for this Study . . . . . 36

5 Mean Scores, Standard Deviations, and t-values ............... . 38

6 Boys and Girls who Did Not Complete Each Test . . . . . . . . . . . . 39 
CHAPTER I

INTRODUCTION AND STATEMENT OF PURPOSE

Introduction

Early childhood is a period of rapid linguistic development. Research examining early language skills shows a wide variation in the rate of acquisition and in the course of development. This wide variation also exists when language development is delayed. Sometimes the reason for these differences is easily identified, as with autism or Down Syndrome. Often, however, the etiology is not readily identifiable, as in children who are normal in every other area of development, yet present with language delay. Although it is generally assumed that individual differences in language acquisition depend largely on variations in learning capacity or environmental conditions, little is known about the actual etiology.

In the population of children reported to have early language delay, boys out number girls by as much as 4-to-1 according to Satz and Zaide (1983) and 5-to-1 according to Whitehurst et al. (1988). The prevalence of other disorders that are related to speech and language is also reported to be higher in boys. Some of these other 
disorders include infantile autism (3.8:1), developmental dyslexia (3.5:1), and stuttering (3.8:1) (Satz \& Zaide, 1983). Six times more boys than girls are also diagnosed as having learning disabilities (Finucci \& Childs, 1981). since there is powerful evidence showing a higher prevalence of males with disorders related to speech and language, the notion of a causal relationship between gender and language disorders is not unfounded.

The identification of predictive factors contributing to early language delay is of significance since children with early language delay are at risk for academic difficulties later on. According to Aram and Nation (1980), nearly half of the school children in their study who were identified as language delayed as preschoolers were not in regular classrooms. Below normal abilities were particularly evident in areas such as reading, writing, and math. Early language delay has also been associated with social and behavioral problems later on, such as inability to attend and to shift focus from one task to another.

Early identification of this at-risk population is paramount so that the likelihood of long-lasting problems in educational, cognitive, and behavioral development may be significantly reduced or even eliminated. Studying gender differences in delayed language development will help illuminate the significance of gender as a reliable 
predictor of language disorders. This will provide valuable insight and direction for speech-language pathologists when developing programs for intervention for the preschooler with language delay.

\section{Statement of Purpose}

The purpose of this study is to determine whether there is a significant difference in the language skills of 3-year-old boys versus 3-year-old girls who were all identified as late-talking toddlers at age 2, that is, do the scores on standardized measures of expressive and receptive language vary significantly between the two groups? Scores from five assessment measures will be used for this study. These measures include the Developmental Sentence Score (DSS), the Expressive one-Word Picture Vocabulary Test (EOWPVT), the Goldman-Fristoe Test of Articulation (GFTA), the Test of Auditory Comprehension of Language-Revised (TACL-R), and the Peabody Picture Vocabulary Test-Revised (PPVT-R).

The research hypothesis for the present study is that there is a significant difference in the language scores of 3-year-old boys versus 3-year-old girls who were identified as late-talking toddlers at age 2 . The null hypothesis is that there is not a significant difference between the language scores of the two groups. 
CHAPTER II

REVIEW OF THE LITERATURE

In this chapter, evidence of gender differences in both delayed and normal developing children is discussed. Theoretical explanations for these differences, including the role of maternal linguistic input, are drawn from the literature. The ramifications of early language delay, which become evident as these children advance to school age, are also discussed. In the final section of this chapter, gender differences seen in language related disorders such as learning disabilities and reading disorders are discussed.

Gender Differences in Normal Language Development

Studies that focus on the development of early language are plentiful and date as far back as 50 years or more. Almost as plentiful as the studies themselves is the diversity in results generated by these studies. While some reveal that differences in language development between boys and girls do not exist, others reveal that they do, and still others reveal conflicting results about where and when these differences occur.

Differences reported in children prior to the age of 
2 include a study completed by Fenson et al. (1994). Fenson et al. reported that females scored slightly higher than males on measures of word comprehension, word production, word combinations, maximum sentence length, and sentence complexity. Differences in communicative development were noted between the ages of 8 months and 30 months. Vocabulary size in particular was found to be larger for girls than for boys up to the age of 2 (Huttenlocher, Haight, Bryk, Seltzer, and Lyons, 1991; Maccoby \& Jacklin, 1974).

Evidence of differences subsequent to 2 years of age includes a study by Mccarthy (1953) that showed that gender differences in favor of girls become apparent when "true" speech begins to emerge, around the second year of life. The number of speech sounds produced was found to be nearly identical until then. Earlier, Irwin and Chen (1946) developed curves that show the number of different speech sounds used by infants up to $21 / 2$ years of age. These curves also show that speech sounds are nearly identical for boys and girls until the age of 2 , at which time the number of different sounds used by girls exceeds the number used by boys. Another study, conducted by Morley in 1965, showed that although there was no significant difference in the age at which first words or 2-3 word phrases were initially used, there was a significant difference in the age at which speech becomes 
intelligible. Girls' speech was found to be intelligible more than 5 months earlier than boys' speech, as determined by the assessment of sequences of sounds in phrases and sentences.

There is also evidence that developmental language differences tend to diminish over time, but again there is great diversity in the evidence. Reports that specify where and when these differences cease to exist reveal data that are inconsistent from study to study. A study by Moore (1967) revealed that initially, around 12 months of age, general language abilities in boys and girls are nearly equal. Then at 18 months, girls exceed boys by a narrow margin, but soon thereafter the boys catch up to and sometimes surpass the girls. Morley (1965) found that the percentage of intelligible speech, which is significantly higher in females than in males at age 2 , is nearly equal in the two groups at age 4. Data reported by Fenson et al. (1994) also reveal a decrease in the differences between the two groups in words produced and in sentence length and complexity at 30 months of age. Maccoby and Jacklin (1974) noted that by the age of 2 , boys catch up to girls in early vocabulary size. One of the more in-depth studies, conducted by Templin (1957), compared boys' and girls' scores in 33 different language areas. She found that, at age 3, boys scored higher than girls in all 33 measures. At age 4, the boys only 
slightly exceeded the girls in articulation, but not in other areas such as vocabulary and verbalization length and complexity.

\section{Possible Explanations for the Differences}

When exploring the possibility of early developmental differences in boys' and girls' language, Moore (1967) explained that while boys' interests are directed toward mechanical things and how they work, girls' interests are directed toward domestic play and personal relationships. He suggested that these differences result in a predisposition for infant girls to respond more readily to auditory stimuli while boys respond more readily to visual stimuli. Mccarthy (1953) stressed the importance of imitative babbling as a highly recognized factor in the establishment of language patterns. She claimed that because the primary caretaker and companion for children of both sexes is most often female, infant girls find verbal communication more satisfying than infant boys. According to Mccarthy, this is because the sound quality of the infant girl's voice is much more like that of the mother whom she has a need to imitate, whereas the infant boy's voice is very different than that of the father whom he has a need to imitate. She referred to this as the "echo reaction" stage in which the baby attempts to approximate his or her babbling sounds to that of the mother. 
More recently, O'Brien and Nagle (1987) suggested that children who play with different types of toys are exposed to different qualities and quantities of language. More specifically, children, typically females, who frequently play with dolls may receive more opportunities to learn and practice language than other children, typically males, who frequently play with vehicles. Huttenlocher et al. (1991) reported that findings of early gender differences, at least in vocabulary growth, suggest the existence of maturational differences in the language capacities of boys and girls, with these differences favoring girls up to at least 2 years of age. This coincides with Moore (1967) who, as previously mentioned, suggested that girls are biologically predisposed to respond to auditory stimuli earlier than boys.

\section{The Role of Maternal Linguist Input}

Linguistic input is a primary source of information for learning verbal language. Copious documentation addresses the existence of a special speech style which is used when talking to infants and toddlers. Some researchers report that mothers "fine-tune" their speech to match the infant's social and affective responsiveness (Murray, Johnson, \& Peters, 1990; Smolak, 1987; Snow, 1972). Murray et al. expanded this idea by stating that the decrease in the mother's mean length of utterance (MLU) from the infant's early months to later months is 
actually a period of "gross-tuning". Then as the infant begins to comprehend language, the mother "fine-tunes" her speech with a further reduction in MLU during the second half of the infant's first year. Phillips (1973) determined that mothers' MLU reaches a "floor" at about 1 year, followed by a progressive increase as the child gains linguistic competence.

According to Snow (1972), mothers' speech differs in many ways when talking to 2-year-olds versus 10-year-olds. She found that when addressing the 2-year-old, the mothers' speech was simpler and more redundant. Also the utterances were shorter in length, and complete sentences were repeated four times more often. Snow found that mothers modify their speech less when talking to children whose responses could not be observed. She suggested that the child plays some role in eliciting the mother's linguistic modifications. Smolak (1987) agreed that maternal speech is influenced by the child's behavior, however, others (Retherford, Schwartz, \& Chapman, 1981) suggested that children change to become more like the mothers. These two views were combined by Tiegerman and Siperstein (1984) who suggested that the linguistic input is shaped by the child, and the adult is acutely aware of and tuned into the child's communicative behavior.

Researchers have also explored the possibility that mothers use language styles that vary in both quality and 
quantity when talking to sons versus daughters. studies which focused on the quantity of maternal input reported conflicting results. Some concluded that mothers tend to speak more to girls than to boys (Cherry \& Lewis, 1978; Halverson \& Waldrop, 1970). Yet others (Cohen \& Beckwith, 1976; Huttenlocher et al., 1991; Schachter, 1979) reported no difference in the amount of mothers' speech to sons versus daughters.

When addressing the quality of maternal input, O'Brien and Nagle (1986) suggested that parents may provide "differential language-learning" opportunities to sons and daughters based on the context of play behavior. Previous research has shown that different toys are associated with different kinds of play behavior (Liss, 1981; O'Brien \& Huston, 1985). These studies tend to agree that doll play is associated with increased talkativeness, whereas truck play is associated with higher physical activity. O'Brien and Nagle (1987) studied linguistic interaction between parent and child in three play contexts: dolls, vehicles, and shape sorters. With the shape sorters, parents' speech was mainly functional, with a lot of directives, attentionals, and praise. Use of nouns, active verbs, and modifiers was lowest in this context. With dolls, parents were more verbal and encouraged more verbalizations from the child as well. Parents' utterances were also longer and 
contained a high proportion of questions. Use of nouns and active verbs was high as was ratio of nouns to pronouns. Number and length of utterances and use of pronouns and verbs while playing with the vehicles was the lowest of the three contexts studied.

Although evidence supporting differences often reveals more rapid language development in girls than boys, there is also evidence to the contrary. Likewise, the evidence with regard to what the differences actually are, and if and when they resolve is also conflicting. At this point, there is inconclusive data for determining whether or not differences between boys' and girls' normal language development actually exist.

\section{Gender Differences and Language Delay}

Research on language delay more often focuses on the subjects' age relative to communication skills, and less often on the relationship between gender and communication skills (Huttenlocher et al., 1991). Morley (1965) looked at sex differences in toddlers who had articulation delays. She looked at two groups of toddlers, one group with "defective development of speech," and a second group with "severe defects of articulation." Her findings revealed a highly significant difference between boys and girls for the age when articulation is acquired in both groups. She also noted that these "defects" tend to 
persist longer in boys than in girls, perhaps even up to the ages of 4 and 5. Evidence to the contrary was reported by Paul (1993). She found that late-talking boys' and girls' articulation scores are very similar at the 3- and 4-year age levels, and that expressive syntax scores, as measured by the Developmental sentence score (DSS), indicate that boys have a greater chance of moving into the normal range than girls at both the 3- and 4-year age levels.

\section{The Role of Maternal Linquistic Input}

Some research shows evidence suggesting that children with delayed language experience a linguistic environment that differs from that of normally developing children (Bondurant, Romeo, \& Kretschmer, 1983; Schodorf \& Edwards, 1983; Tiegerman \& Siperstein, 1984). Although mothers of language delayed children provide much of the same linguistic information as mothers of normally developing children, there are some important linguistic adjustments made when speaking to children with language delay (Bondurant, et al., 1983). Bondurant et al. reported that these adjustments involve reduction in mean length of utterance, the number of questions used, and the amount of acceptance provided. Increases were noted in the number of directions and the amount of rejection given. Paul and Elwood (1991) reported that the only difference in mothers' speech to language delayed children was in the 
frequency with which expansions and extensions were used. However, the ratio of expansions and extensions used to the number of child utterances was similar to that seen in normally developing children, indicating that mothers do expand for these children, but the language delayed children simply give the mothers fewer utterances to expand upon.

Cunningham, Siegel, van der Spuy, Clark, and Bow (1985) conducted a study that looked at maternal input and normal versus delayed language development. They found that maternal speech to boys with delays in both language expression and comprehension was significantly less complex than maternal speech to normally developing boys. This study did not include a comparison of girls with normal and delayed language.

\section{Outcomes of Early Lanquage Delay}

Numerous studies have been conducted to determine if language delay in preschool children is a reliable predictor of later language and academic difficulties (Aram, Ekelman, \& Nation, 1984; Aram \& Nation, 1980; Scarborough \& Dobrich, 1990; Silva, Williams, \& McGee, 1987). Aram and Nation looked at language delayed preschoolers and reported that approximately $40 \%$ continued to have some speech and language difficulties into their school years, were not in regular classrooms, and showed below-normal achievement in reading and math. This led to 
the conclusion that language delayed preschoolers do not "grow out" of their language problems. Scarborough and Dobrich found evidence that indicated that language delayed preschoolers who had achieved normal or nearnormal language skills by age 5 were at risk for problems with reading ability later on. Although articulation deficits appear to resolve spontaneously by the age of 5 (Scarborough \& Dobrich, 1990; Whitehurst et al., 1991; Winitz, 1959), Shriberg and Kwiatkowski (1988) reported that nearly one-third of preschool children who presented with articulation difficulties required special education services once in school. This appeared to be true even when the articulation difficulties no longer existed. Rosenthal (1970) suggested that speech and language disorders in children are related to later educational achievement, vocational status, and social adjustment. A study conducted by Silva et al. (1987) confirmed the importance of early language delay as a predictor of lower than average intelligence and reading ability as well as increased behavior problems. Data collected by Aram et al. (1984) indicated that language disorders in children are often not confined to oral language, or to the early childhood years. Rather, the majority of children in their study continued to present with "broadly based language-learning problems" later on, and as a result, encountered educational and social consequences as much as 
10 years later.

In a longitudinal study conducted by walker, Greenwood, Hart, and Carta (1994), results showed that the number of different words used, MLU, and IQ at 36 months of age were significantly related to both expressive and receptive language skills in kindergarten. Measures taken at elementary school age also revealed that receptive and expressive language, reading, and spelling skills were related to prior measures of language and IQ obtained between 7 and 36 months of age. Low socioeconomic status was also found to be a significant variable that inhibited development of language and academic skills. Whitehurst et al. (1994) looked at the relationship between literacy experiences and later reading skills in preschoolers attending Head start. They reported that although literacy skills in this population are typically one standard deviation below the national average, increased exposure to books and reading materials significantly enhanced pre-academic literacy skills such as letter recognition, concepts of print, and writing.

Gender Differences and Language Related Disorders Learning Disabilities

There are many more males identified with learning disabilities (LD) than females. In a review of the literature by Finucci and Childs (1981), it was found that 
the commonly reported ratio of males to females ranged from $4: 1$ to $6: 1$.

The most predominant characteristic seen in children with learning disabilities (LD) is an inability to learn to read, spell, and manage language processes which depend on a system of symbols, such as letters, words, and sentences (Kirk \& Gallagher, 1983). Denckla (1983) stated that children with LD enter school with critical deficits in skills such as phonetic analysis, spelling, following sequences of directions, sequential organization of writing, and selective attention.

When comparing the intellectual abilities of males and females in the LD population, the Weschler Intelligence Scale for Children-Revised (WISC-R) reveals that males show significantly higher full scale intelligence quotients (FSIQ) than females (Phipps, 1982; Ryckman, 1981; Vogel \& Walsh, 1987) . Bradbury, Wright, Walker, and Ross (1975) studied elementary school students with learning disabilities. They found that males had higher verbal intelligence quotients (VIQ), performance intelligence quotients (PIQ), and FSIQ. Similar findings were reported by Eno and Woehlke (1980) and Tittemore, Lawson, and Inglis (1985). It was noted that coding, a performance subtest, was the one area where females excelled. It was hypothesized that this was due to superior fine motor skills, finger dexterity, eye-hand 
coordination, visual-motor abilities, attention span, and concentration. Female superiority in these types of tasks is seen in children without LD also.

Several researchers have documented that children with LD are deficient in most aspects of semanticsyntactic processing, comprehension and production of morphology (Denckla \& Rudel, 1976; Donahue, 1984; Wiig \& Semel, 1984), vocabulary development (Wiig \& Semel, 1984), and word retrieval (Denckla \& Rudel, 1976). However, little if any investigation has been done regarding gender differences in these areas of language.

\section{Reading Disorders}

More males are identified with reading disorders (RD) than females. Finucci and childs (1981) cited variations in male-to-female ratios as high as $15: 1$ and as low $3: 1$, with the majority of reported ratios in the neighborhood of 5:1. Children with RD tend to fall further behind their normal reading peers as they grow older, resulting in increased prevalence rates in older children (Benton \& Pearl, 1979).

Shaywitz, Shaywitz, Fletcher, and Escobar (1990) suggested that the higher proportion of males with RD versus females is due in part to referral bias. Their data show that there is anywhere from two to four times more school-identified children with RD than those identified by scores on the WISC-R. Shaywitz et al. 
explained that teachers rate boys as significantly more active, more inattentive, and less dexterous. They are also more often seen by their teachers as having problems with behavior, language, and academics in general as compared to their female counterparts. Therefore, boys are more readily identified as $\mathrm{RD}$ than girls. Despite teacher reports of difficulties in the classroom, Shaywitz et al. reported that measurements of overall ability and achievement are comparable between boys and girls.

When girls are identified as RD, they are often more severely impaired in reading before being identified (Phipps, 1982). Kashani, Chapel, Ellis, and Shekim (1979) compared boys and girls, all of normal intelligence, and found that more boys were referred for RD because of hyperactivity and/or behavior disorders, and girls were referred for language and learning disorders. However, when comparing levels of overactivity, attention span, and restlessness, no differences were found between the two groups.

A number of researchers have investigated the possibility of a biological explanation for gender differences in RD. Witelson (1976) suggested that at the time when children are learning to read, the cognitive processes required for reading were differentially organized in the brains of boys and girls. This theory has since been discounted (Naylor, 1980; Witelson, 1977). 
It has also been suggested that hormonal and neuroendocrine factors are associated with sex differences seen in temperament, cognitive styles, and cognitive abilities. It has also been hypothesized that there is a relationship between these factors and hyperactivity and developmental dyslexia (Weintraub, 1981).

\section{Summary}

Most researchers find different rates and patterns of normal language development, but the data are not consistent with regard to where and when these differences occur. The evidence is also inconsistent as to the outcome of these differences. Do they tend to diminish, and if so, when? Some report that the larger vocabularies seen in very young females are no longer evident by the age of 2 (Huttenlocher et al. 1991; Maccoby \& Jacklin, 1974), and others say by the age of 4 (Morley, 1965). When language delayed children are compared to their normally developing peers, there are some similarities as well as some differences observed in developmental patterns. Morley (1965) reported that language delays tend to persist longer in girls, and Paul (1993) reported that by age 4 , boys with a history of language delay were more likely to be in the normal range than were girls with this history. It is suggested that linguistic environment differs between boys and girls (O'Brien \& Nagle, 1987). 
Objects girls tend to play with, such as dolls, elicit more verbal interaction than objects boys play with, such as trucks. The linguistic environment also varies between normally developing and language delayed children (Bondurant et al., 1983; Schodorf \& Edwards, 1983; Tiegerman \& Siperstein, 1984). Mothers adjust their speech to match the communicative behavior of the child; therefore, the child with delayed language skills not only elicits less linguistic input from the mother, but also a less optimal language style.

It is generally agreed that early language delay tends to persist into the school years. Children with early language delay have a higher incidence of learning disabilities and reading disorders later on. Approximately $40 \%$ of the children identified as having early language delay are not in regular classrooms and have below-normal math and reading skills (Aram \& Nation, $1980)$.

The prevalence of language delay, learning disabilities, and reading disorders is significantly higher in males than in females. More boys are identified with both learning disabilities and reading disorders during the school years (Finucci \& Childs, 1981); however, girls tend to be more severely impaired in reading before they are identified (Phipps, 1982).

Although some studies examine gender differences, the 
majority look at chronological age in relation to variances in language development. A review of the literature indicates the need for additional research that emphasizes the role of gender and its relationship to language disorders. 
CHAPTER III

METHODS AND PROCEDURES

subjects

\section{Selection of Subjects for the Present study}

The present study is a secondary analysis of data that was previously collected for the Portland Language Development Project (PLDP) and for a smaller, subsidiary study of the PLDP. The PLDP is a longitudinal study investigating the long-term prognosis of late-talking toddlers, and the subsidiary study, hereafter referred to as the girls study is a two-year project investigating the communication skills of late-talking girls. Both studies are under the direction of Dr. Rhea Paul, professor of Speech and Hearing Sciences at Portland State University. Normal subjects, as well as late-talkers (LTs), were included in the PIDP, but only those subjects who were determined to be LTs at 20-34 months of age were considered for possible inclusion in the present study. Final subject selection for this study was accomplished by examining the data in the files of these pre-existing subjects. Subjects selected for the present study, 23 boys and 16 girls, include all LTs from the PLDP and the girls' study who had expressive vocabularies of less than 
50 words at 20-34 months and were present for follow-up evaluation at the age of 3 .

\section{Subject Recruitment for the PLDP and Girls study}

Subjects for the PLDP and girls study were initially identified by two methods. The first method was through three local pediatricians' offices. Parents bringing their children in for 18 month and 24 month well-baby visits were asked to complete a preliminary questionnaire if they were interested in participating in the study. The second method was through newspaper and radio advertisements requesting boys and girls who were 2 years old but not talking. Parents who responded to the newspaper and radio advertisements were given the same questionnaire as the parents visiting the pediatricians' offices. Information obtained on the questionnaire included the parents' occupations, the child's birthdate, the number of different words the child used, and whether or not the child used word combinations. A total of 300 completed questionnaires were collected.

Criteria for eligibility in the IT group were vocabularies of less than 50 words or no two-word combinations at 20-34 months, by parent report. The remaining candidates were reported to have vocabularies exceeding these amounts and were considered eligible for the control (normal) group. Subjects for the two studies were then drawn from the pool of candidates and divided 
into two groups: normal and LT. All LTs were included, and a control group matched for age, sex, race, and socioeconomic status was selected from the pool of subjects whose parents reported more than 50 words on the questionnaire. Socioeconomic status was based on Myers and Bean's (1968) adaptation of Hollingshead's four-factor scale of social position.

To confirm placement in the two diagnostic groups (normal and LT), Rescorla's Language Development Survey (LDS), which consists of 300 of the most frequently appearing words in a child's early expressive vocabulary, was then administered to parents of children participating in the study. Rescorla (1989) reported that the LDS is a valid and reliable tool for indexing expressive vocabulary size and identifying language delay in this age group.

All subjects passed a hearing screening in a sound field at $25 \mathrm{~dB} \mathrm{HL}$, and informal observation ruled out any physical handicaps or other disabilities, such as autism.

\section{Description of Subjects for the Present study}

Subjects identified as LTs at intake for the PLDP and for the girls study were seen yearly for reevaluations. Subjects for the present study were selected from the subjects in these larger cohorts of LTs who were present for follow-up assessment at age 3 .

The total number of subjects selected for the present study is 39,23 boys and 16 girls. Demographic 
information for these subjects is presented in Table 1. There were no significant differences on any of the variables included in Table 1.

Table 1

Demographic Means and Standard Deviations for subjects Used in the Present study

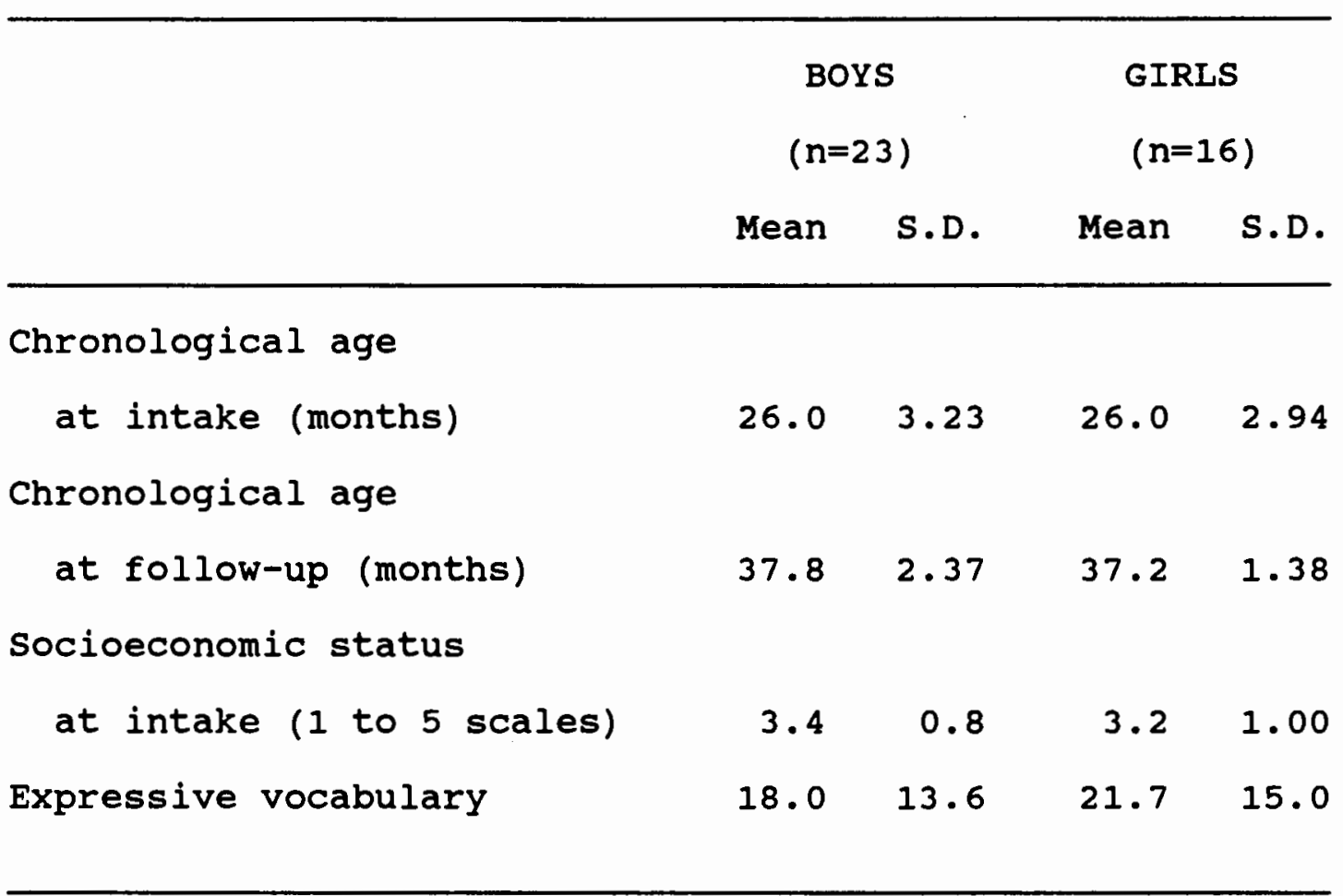

Note. Expressive vocabulary was measured by the Language Development survey (LDS).

\section{Procedures}

Subjects in the PLDP and in the girls study were seen for follow-up evaluations at 3 years of age. These evaluations were conducted at an earlier date by trained 
graduate research assistants, and the data were retrieved from the subjects' files for use in the present study. Tests administered at age 3 include the Developmental Sentence Score (DSS), the Expressive one-Word Picture Vocabulary Test (EOWPVT), the Goldman-Fristoe Test of Articulation (GFTA), the Peabody Picture Vocabulary TestRevised (PPVT-R), the Test of Auditory ComprehensionRevised (TACL-R), the Northwest Syntax screening Test (NSST-E), the Preschool Language Scale (PLS), the Test of Language Development-Primary (TOLD-P), and the Vineland Adaptive Behavior Scale (VABS). Tests used for the present study were drawn from this larger group of tests and include the DSS, EOWPVT, TACL-R, PPVT-R, and GFTA.

Language samples for the DSS were collected during free play between the mother and child. These ten-minute spontaneous language samples were audiotaped using a sony model cassette tape recorder, sony ECM-D8 electret condenser microphone, and sony brand cassette tapes. Each subject's language sample was transcribed by hand and later analyzed by trained graduate research assistants using Lee's (1974) DSS. The TACr.R, EOWPVT, PPVT-R, and GFTA were administered and scored by the same graduate research assistants. Administration was done according to the instructions outlined in each test manual. Tests were administered to each subject individually in clinic rooms at Portland State University Speech and Hearing Sciences 
Department.

$$
\text { Instrumentation for the Present study }
$$

The standardized tests used for comparison in the present study are shown in Table 2. All tests were obtained at age 3 as part of the PLDP and the girls study, and the data were later retreived for analysis in this study.

\section{Developmental Sentence Score}

The DSS (Lee, 1974) is a norm-referenced instrument, standardized on 200 children from the states of Illinois, Maryland, Michigan, and Kansas. All but 3 children were from middle-class families. There were 10 children at every 3-month interval between the ages of 2 years and 6 years 11 months. The DSS assesses syntactic complexity based on eight grammatical categories: indefinite pronouns, personal pronouns, main verbs, embedded secondary verbs, negative markers, conjunctions, interrogative reversals, and wh-question forms. The utterances are assigned points for each category based on developmental level of complexity. A sentence point is also given for each utterance produced correctly, according to adult standards for grammatical form. An attempt mark is used instead of a point to note that the structure was attempted, although used incorrectly. 
Table 2

Standardized Measures Used for Comparison in This Study

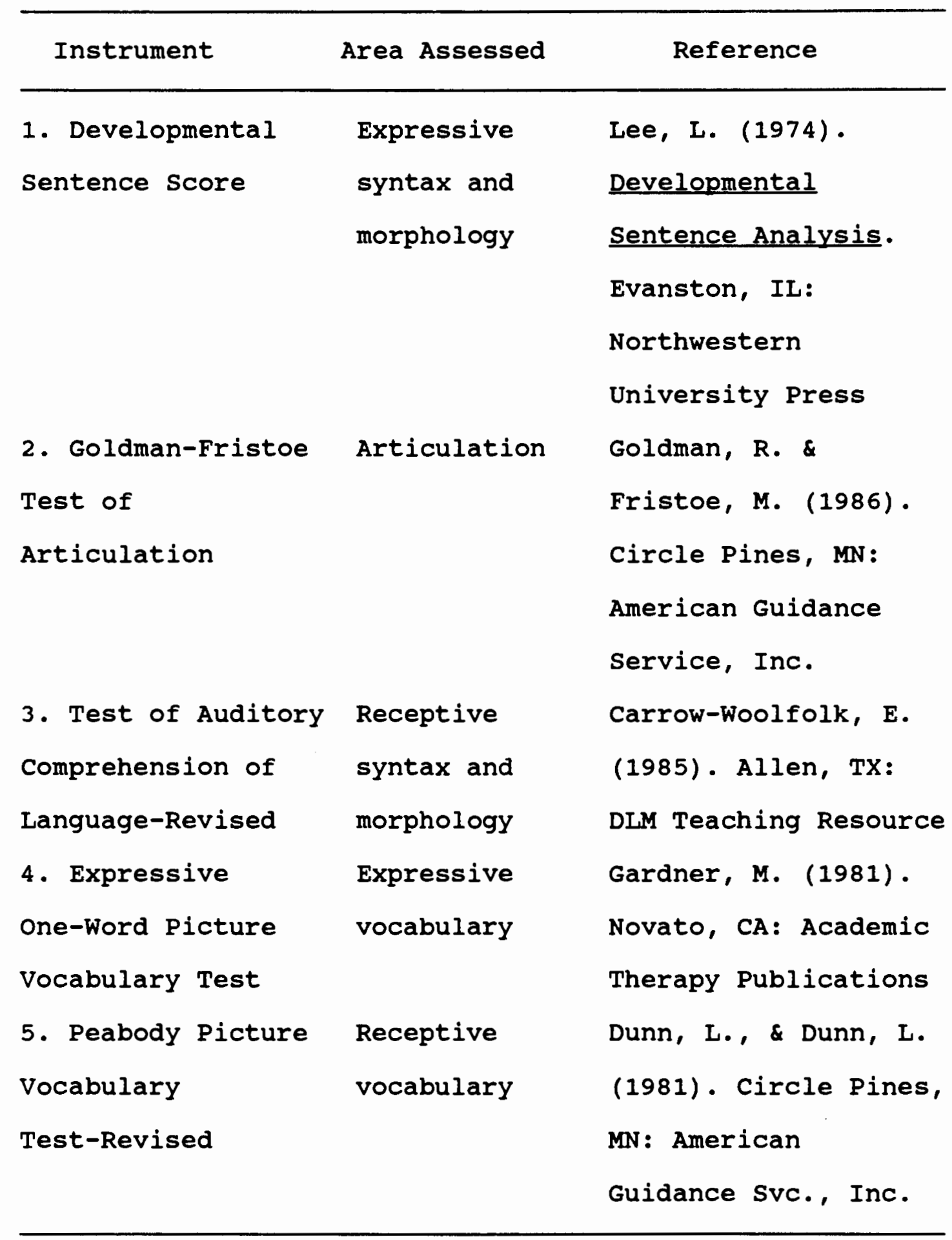


Internal consistency of the DSS is .71, and splithalf reliability is .73 . Interrater reliability, using the scores from 2 different judges, showed no significant differences.

\section{Goldman-Fristoe Test of Articulation}

The GFTA, developed by Goldman and Fristoe (1986), assesses articulation of the consonant sounds in spontaneous and imitative speech by examining sounds-inwords, sounds-in-sentences, and stimulability for misarticulated sounds. Production of sounds in initial, medial, and final position is evaluated. Picture cards are used to elicit sounds-in-words, and narrative stories combined with picture cards are used to elicit sounds-insentences. Production of 11 consonant blends is also included, with the earlier developing phonemes listed first, followed by those which are acquired later. stimulability is tested using sounds-in-syllables. standardization was based on a stratified sample of 38,884 children, grades 1 through 12, from across the United states who were participating in The National Speech and Hearing survey conducted in 1971. The GFTA was one measure used to collect data for this survey. Norms for younger children, ages 2.0 through 5.11, which were obtained several years later were based on the sample of subjects used to standardize the Khan-Lewis Phonological Analysis. 
Test-retest reliability for the GFTA is $95 \%$ and $94 \%$ for the sounds-in-words and sounds-in-sentences subtests, respectively. Interrater reliability is 928 for presence or absence of sound and $88 \%$ for type of production. Interrater reliability for sounds-in-words is $91 \%$ for both presence or absence of sound and type of production.

Raw scores and percentile rank can be used for interpretation of results in both the sounds-in-words and syllable stimulability subtests. For this study, the percentile rank for the sounds-in-words subtest was used for comparison between the two groups of subjects. A percentile rank of .01 was used for subjects who did not respond or could not complete the sounds-in-words subtest due to inability to attend.

\section{Test for Auditory Comprehension of Language-Revised}

The TACL-R (Carrow-Woolfolk, 1985) was designed to identify receptive language disorders by assessing auditory comprehension of semantic relations, grammatical forms, and elaborated sentences. Verbal stimuli in the form of words or sentences are read, and the subject must point to the one picture out of three that illustrates the stimulus presented. Verbal stimuli within each subtest progress from simple to complex, and administration continues until three consecutive incorrect responses occur.

The TACL-R was standardized using 1,003 subjects, 
ages 3.0 through 9.11 , selected by stratified random sampling. Each age level was stratified by family occupation, ethnic origin, age, sex, community size, and geographic distribution. Reported reliability measures include internal consistency ranging from .91 to .97 , and test-retest reliability ranging from .89 to .95 .

The TACL-R provides norm-referenced information for interpretation of results including percentile rank by age and grade, conversion tables for standard scores, standard errors of measurement according to age and grade, and age equivalent scores. Non-normalized scores are also included. For this study, the standard score was used for comparison between the two groups of subjects. A standard score of 69 was used for subjects who did not respond or who could not complete the test due to inability to attend.

\section{Expressive One-Word Picture Vocabulary Test}

The EOWPVT (Gardner, 1990) was designed to assess a child's acquired expressive one-word vocabulary. It consists of picture cards containing one or more items that must be named. Scoring begins where eight consecutive correct responses are recorded and ends where six consecutive incorrect responses are recorded.

Standardization was based on performance of 1,118 children, ages 2.0 through 11.11 , in the San Francisco Bay Area. At least 100 children were in each 12-month age 
group, with the exception of the 2.0-2.11 and 3.0-3.11 age groups, which contained 53 and 77 , respectively. Splithalf reliability is reported for each age group and ranges from .87 to .96 , with a median of .94 . Content validity was obtained through selection of English words that could be illustrated without ambiguity, and for which usage was not associated with race, culture, region, creed, or sex. Item validity was obtained through retention of words most likely to be acquired as chronological age increased, and through correlation of scores with the Peabody Picture Vocabulary Test (PPVT). IQ scores from the EOWPVT were also compared to those from the PPVT.

Four types of scores can be derived from the raw score, including mental age, deviation IQ, stanine, and percentile rank. For this study, the deviation IQ score based on the results of all subtests was used for comparison between the two groups of subjects. A deviation IQ of 55 was used for subjects who did not respond or could not complete the test due to inability to attend.

Peabody Picture Vocabulary Test-Revised

The PPVT-R, a measure of receptive vocabulary, was developed by Dunn and Dunn (1981). It consists of plates containing four pictures, one of which is an illustration of the stimulus word. The stimulus words are made up of object words (nouns) and action words (gerunds), with 
level of difficulty ranging from easy for 2-year-old to hard for adults. The starting point is considered the point where 8 consecutive correct responses are given, and the ceiling is reached when 8 consecutive responses contain 6 errors.

The PPVT-R was standardized on a sample of 4,200 children and youth, ages 2.6 through 18.11 years. The sample was divided into 21 age groups, nine 6-month age groups for those below age 7 , and 12 age groups for those age 7 and above. Each age group contained 200 subjects, 100 females and 100 males. The sample was drawn from the four regions of the continental United States, as defined by the 1970 U.S. Census. Occupational status, ethnic background, and community size were also among the stratification criteria used. Split-half reliability for children and youth ranges from .67 to .88 , with a median of .80 , and for adults the range is .80 to .83 , with a median of .82 . Test-retest reliability shows that stability of scores decreases with time, from .75 for short-term stability to .59 for long-term stability defined as more than 1 year. Content validity was obtained through restriction of words that could not be illustrated without ambiguity. Nineteen content categories were used to obtain a good cross-section of words drawn from an initial pool of 3,885 words. Raw scores can be converted to standard scores, 
percentile ranks, and stanines. Standard errors of measurement and developmental age norms are also reported. For this study, the standard score was used for comparison between the two groups of subjects.

$$
\text { PLDP Reliability }
$$

The standardized tests used for the PLDP were administered by trained graduate students in speechlanguage pathology. Interrater reliabilities of the scores for each test as administered for the PLDP are shown in Table 3 .

Table 3

Interrater Reliability for the PLDP

\begin{tabular}{lc}
\hline Instrument & Reliability \\
\hline EOWPVT & 998 \\
GFTA & $90 q$ \\
PPVT-R & $100 q$ \\
TACL-R & $100 q$ \\
DSS & 938 \\
\hline
\end{tabular}

Interrater reliability of the DSS was obtained by random selection of 108 of the taped language samples and independent transcription of these samples by two graduate research assistants. The two transcriptions were 
compared, word-for-word, revealing a transcription reliability of 918 . Interrater reliability of the scores for all other assessment measures was obtained using a comparison of scores from independent test administrations by two graduate research assistants.

\section{Data Analysis}

Data used in this study were taken from the data collected as part of the PLDP and the girls study. The type of score recorded for each instrument, and then used for the purpose of this study, is shown in Table 4 . Although an attempt was made to administer all tests to all subjects, some tests were not completed due to the subject's lack of response or inability to attend long enough to complete the test. In these cases the standard score for zero correct, as determined by the test manual for each instrument, was used. A percentile rank of .01 was used for the GFTA. The standard scores for zero correct for each instrument are also shown in Table 4. The scores each subject obtained on each of five different assessment measures were recorded from the individual subject's file. These individual scores were used to calculate a mean score for the boys and a mean score for the girls on each of the five measures of assessment. A two-tailed t-test was conducted using the aforementioned mean scores to identify differences between 
the two groups on each measure of assessment.

Table 4

Types of Scores Used for the Present Study

\begin{tabular}{clc}
\hline & Type of & Score Used for \\
Instrument & Score & 0 correct Responses \\
\hline DSS & Raw Score & NA \\
GFTA & Percentile Rank & 01 \\
TACL-R & Standard Score & 69 \\
EOWPVT & Standard Score & 55 \\
PPVT & Standard Score & NA \\
\hline
\end{tabular}




\section{CHAPTER IV \\ RESULTS AND DISCUSSION}

Results

The purpose of this study was to determine if the language skills of late-talking toddlers differ between boys and girls at the age of 3 . Test scores of five different standardized assessment measures were analyzed using a two- tailed t-test. The research question asked was: Is there a significant difference in the language scores of 3-year-old boys versus 3-year-old girls who were identified as late-talking toddlers at age 2?

The means and standard deviations for each of the five dependent measures were computed for the two subject groups to determine if there was a statistically significant difference between the boys' and girls' scores. The results show a significant difference at the .05 level of confidence between the two groups only on the EOWPVT which measures expressive one-word vocabulary. Differences on all other measures of assessment were not statistically significant at the .05 level. The results of the statistical analysis are presented in Table 5. Although not statistically significant, the boys' scores were consistently higher than the girls' scores on all 
other instruments. The only score that revealed a delay for the group of boys was the DSS. Delay is defined as being below the 10th percentile. The girls' scores on the DSS, the EOWPVT, and the GFTA all indicated delays.

Table 5

Mean Scores, Standard Deviations, and $t$-Values

\begin{tabular}{lrrrrrrrr}
\hline & \multicolumn{3}{c}{ BOYS } & \multicolumn{5}{c}{ GIRLS } \\
& \multicolumn{3}{c}{$(\mathrm{n}=23)$} & \multicolumn{3}{c}{$(\mathrm{n}=16)$} \\
& Mean & S.D. & Delay? & Mean & S.D. & Delay? & $t$-Value \\
\hline DSS & 2.41 & 2.23 & Yes & 1.70 & 2.57 & Yes & 0.91 \\
EOWPVT & 97.30 & 19.57 & No & 80.69 & 22.66 & Yes & 2.44 * \\
GFTA & 15.61 & 15.82 & No & 8.69 & 20.91 & Yes & 1.18 \\
PPVT-R & 98.69 & 20.43 & No & 89.37 & 20.24 & No & 1.41 \\
TACL-R & 94.87 & 15.87 & No & 91.62 & 27.36 & No & 0.47 \\
\hline
\end{tabular}

$d f=37$

* Significant beyond .05 level of confidence.

Standard deviations for the girls were larger than for the boys on all instruments, except the PPVT-R.

Administration of all assessment measures was not completed for all subjects. This was due to the subject's lack of response or inability to attend long enough to complete the test. Table 6 shows the numbers and percentages of boys and girls who did not complete each assessment measure. 
Table 6

Boys and Girls Who Did Not Complete Each Test

\begin{tabular}{lcccc}
\hline Instrument & Boys $(q)$ & Girls $(q)$ \\
\hline EOWPVT & 1 & $(4)$ & 3 & $(19)$ \\
GFTA & 1 & $(4)$ & 5 & $(31)$ \\
TACL-R & 1 & $(4)$ & 1 & $(6)$ \\
PPVT-R & 0 & $(0)$ & 0 & $(0)$ \\
DSS & 9 & $(39)$ & 10 & $(63)$ \\
\hline
\end{tabular}

Discussion

The results of this study revealed a significant difference between the mean scores for expressive one-word vocabulary, as measured by the EOWPVT, of 3-year-old boys and girls who were identified as LTs at the age of 2 . No significant differences were found between genders for any other areas of language examined including syntactic complexity as measured by the DSS, articulation of consonant sounds in words as measured by the GFTA, auditory comprehension of semantic relations, grammatical forms, and elaborated sentences as measured by the TACL-R, or receptive vocabulary as measured by the PPVT-R.

Although the only significant difference found in this study was on the EOWPVT, the results were sufficiently consistent to reveal a trend favoring the 
boys. This trend is evident in several ways. First, the means for the boys' scores were consistently found to be higher than the means for the girls' scores. Second, the data on four out of five assessment measures indicated that there was a higher percentage of girls who did not respond or who could not complete the test. The PPVT-R was the only measure of assessment completed for all subjects in this study.

The data from this study shows that the boys' expressive vocabulary size reaches normal and exceeds that of the girls by age three.

Studies on the patterns of delayed language development have shown that expressive vocabulary size is the first aspect of the delay to resolve and is typically normal by age 3 (Paul, 1993; Whitehurst et al. 1991). The present results indicate that late-talking girls are slower to catch up in this aspect of development than are boys. Moreover, their generally lower scores on all measures suggest that their rate of "catching up" is slower than that of their male counterparts. Paul (1993) showed that a small group of girls $(n=8)$ with delayed expressive language were less likely than boys to move into the normal range by school age. Results of the present study, which included twice as many girls $(n=16)$, support Paul's findings that boys' expressive language improves more rapidly than that of girls with a history of 
slow language development.

The fact that higher percentages of girls were not able to complete 4 out of 5 assessment measures lends weight to this conclusion. The larger standard deviations seen in the female subjects suggest less homogeneity in this population. This larger variation could account for the failure to find significant differences on the measures used. 


\section{CHAPTER V \\ SUMMARY AND IMPLICATIONS}

summary

The purpose of this study was to investigate the language development of 3-year-olds who had an expressive vocabulary of less than 50 words at 20-34 months of age. Five assessment measures were utilized and compared between boys and girls to see if there was a significant difference between the mean scores of the two groups on each of the five instruments. The first measure, the Developmental Sentence Score (DSS), assesses syntactic complexity based on 8 grammatical categories: indefinite pronouns, personal pronouns, main verbs, embedded secondary verbs, negative markers, conjunctions, interrogative reversals, and wh-question forms. The second measure, the Goldman-Fristoe Test of Articulation (GFTA), assesses articulation of the consonant sounds in spontaneous and imitative speech by examining sounds-inwords, sounds-in-sentences, and stimulability for misarticulated sounds. For this study, only spontaneous speech for sounds-in-words was used. The third measure, the Test for Auditory Comprehension of Language-Revised (TACL-R), assesses auditory comprehension of semantic 
relations, grammatical forms, and elaborated sentences. The forth measure, the Expressive One-Word Picture Vocabulary Test (EOWPVT), assesses acquired expressive one-word vocabulary. The fifth measure, the Peabody Picture Vocabulary Test (PPVT-R), assesses receptive vocabulary.

Participants in this study were 393 -year-old subjects drawn from the larger cohort of late-talkers (LTs) in the Portland Language Development Project (PLDP) and from the girls study. All subjects for this study failed to meet the criteria for normal language development, according to parent report, by exhibiting an expressive vocabulary of less than 50 words at 20-34 months of age. All subjects passed a hearing screening, and had no other observable disabilities or physical handicaps.

A two-tailed $t$-test for dependent means was computed to determine if there was a statistically significant difference between the boys' scores and the girls' scores on five language assessment measures. Results revealed a difference significant beyond the .05 level of confidence for the EOWPVT only. Although only one instrument revealed a significant difference, the mean scores for the boys were higher than the mean scores for the girls on all five assessment measures.

Results of this study do not decisively confirm or 
rule out the possibility of gender as a reliable predictor of early language delay. However, the data do suggest a trend favoring boys. This trend is made apparent by the consistently higher mean scores for the boys, and higher percentages of boys in each assessment measure who responded to and completed each test.

\section{Implications}

\section{Clinical}

These data showed a significant difference in the mean scores for expressive one-word vocabulary between late-talking boys and girls. Although the boys' mean scores were consistently higher than the girls' mean scores for all other assessment measures, these other differences were not significant. There is, however, evidence of a trend favoring the boys. This trend favoring the boys is consistent with the already existing evidence that girls identified as reading disordered or learning disabled are typically more severely affected than boys (Phipps, 1992). This is true for autism also (Lord, Schopler, \& Revicki cited in Paul, 1993).

From a clinical perspective, it is important to explore the extent to which children with language delay are at risk for chronic deficits. This information would provide valuable insight when determining whether or not intervention would be beneficial. Examining gender 
differences in the developmental pattern and rate of language acquisition will help to identify those children at risk for chronic deficits.

The results of the present study indicated that girls who present with language delay at the age of 2 , are likely to still be delayed in many areas at the age of 3 . The data also revealed that even though boys may be more severely delayed than girls at age 2 , they tend to outgrow this delay more readily than girls, particularly in the area of expressive vocabulary. Paul (1993) also reported that girls are less likely than their male counterparts to simply grow out of a language delay (Paul 1993).

At this time, there is no definitive protocol for determining whether to recommend language intervention for girls or boys with language delay or to wait and see if the they will outgrow the delay. Whitehurst, et al. (1991) drew the conclusion from current research on 2year-old LTs that when hearing, intelligence, and understanding of language are all normal, then the child's expressive language will also reach normal limits without intervention. However, communicative ability is known to affect other domains such as education, cognition, and behavior. Finucci and Childs (1981) reported that boys, more often than girls, are identified with problems in these areas later on. A conclusion that can be drawn, therefore, is that girls would benefit from intervention 
to catch up with early language development, and boys would benefit from intervention to facilitate development in these other domains.

\section{Research}

There is an overwhelming supply of data examining both normal and delayed early language development. The problem is these data are inconclusive. Some data suggest no significant differences between boys and girls; other data suggest differences, but give conflicting evidence in regard to when and where these differences occur and what the outcome will be. Like most of the studies examining delayed language development, the data from this study are not conclusive on their own. This study only looked at differences between boys and girls in language skills as measured on certain standardized tests given at the age of 3. When combined with data from similar studies, however, a larger picture of the developmental progress of this population can be seen.

Further research would benefit from a larger sample size than was used for this study. Although the sample size for this study was somewhat larger than those utilized in many similar studies, the standard deviations found, particularly for the girls, were relatively large and may have affected the power of the statistics used. A larger group of subjects would provide a greater degree of statistical power. This increased power could serve to 
resolve the controversies surrounding the significance of early language delay and what role, if any, gender plays in early identification of children at risk.

Longer term follow-up studies would also provide more conclusive data. This is especially true for the female population since more boys are identified with language delay, and, therefore, fewer girls are included in this type of study. The data presented in this study revealed that girls to not recover from language delay as quickly as their male counterparts. This finding supports the need for additional longitudinal studies involving girls. Longitudinal studies conducted in the past have shown that children with a history of developmental language delay often demonstrate difficulties in academic, social, and behavioral domains later on (Aram, Ekelman, \& Nation 1984; Aram \& Nation 1980). Because language skills serve as a foundation for the development of these other domains, the contributions of further longitudinal studies can only increase our knowledge about long-term consequences, and enhance our ability to inhibit the extent and degree to which these consequences become deficits. 


\section{REFERENCES}

Aram, D., Ekelman, B., \& Nation, J. (1984). Preschoolers with language disorders: 10 years later. Journal of Speech and Hearing Research, 27, 232-244.

Aram, D., \& Nation, J. (1980). Preschool language disorders and subsequent language and academic difficulties. Journal of Communication Disorders, 13, 159170 .

Benton, A., \& Pearl, D. (1978). Dyslexia: An appraisal of current knowledge. New York: Oxford University Press.

Bondurant, J., Romeo, D., \& Kretschmer, R. (1983). Language behaviors of mothers of children with normal and delayed language. Lanquage, Speech, and Hearing Services in Schools, 14, 233-242.

Bradbury, P., Wright, S., Walker, C., \& Ross, J. (1975). Performance on the WISC as a function of sex of $E$, sex of $S$ and age of $S$. Journal of Psychology, 90, 51-55.

Carrow-Woolfolk, E. (1985). Test for auditory comprehension of language-revised. Allen, TX: DLM Teaching Resources.

Cherry, L., \& Lewis, M. (1978). Differential socialization of girls and boys: Implications for sex differences in language development. In $\mathrm{N}$. Waterson \& $\mathrm{C}$. Snow (Eds.), The development of communication (pp. 189197). New York: Wiley.

Cohen, S., \& Beckwith, L. (1976). Maternal language in infancy. Developmental Psychology Monograph, 12, $371-$ 372 .

Cunningham, C., Siegel, L., van der Spuy, H., Clark, M., BOW, S. (1985). The behavioral and linguistic interactions of specifically language-delayed and normal boys with their mothers. Child Development, 56, 1389-1403.

Denckla, M. (1983). Learning for language and language for learning. In U. Kirk (Ed.), Neuropsychology of language reading and spelling (pp. 33-43). New York: Academic Press. 
Denckla, M., \& Rudel, R. (1976). Naming of object drawings by dyslexic and other learning disabled children. Brain and Lanquage, $\underline{3}, 1-16$.

Donahue, M. (1984). Learning disabled children's comprehension and production of syntactic devices for marking given vs. new information. Applied Psycholinguistics, $5,101-116$.

Dunn, L. \& \& Dunn, L. (1981). Peabody picture testrevised. Circle Pines, MN: American Guidance Service, Inc.

Eno, L., \& Woehlke, P. (1980). Diagnostic differences between educationally handicapped and learning disabled students. Psychology in the schools, 17, 469-473.

Fenson, L., Dale, P., Reznik, J., Bates, E., Thal, D., \& Pethick, S. (1994). Variability in early communicative development. Monographs of the society for Research in Child Development, 59, 1-189.

Finucci, J., \& Childs, B. (1981). Are there really more dyslexic boys than girls? In A. Ansara, N. Geschwind, A. Galaburda, M. Albert, \& N. Gartrell (Eds.). Sex differences in dyslexia. Baltimore, MD: Orton Dyslexia society.

Gardner, M. (1979). Expressive one-word picture vocabulary test. Navato, CA: Academic Therapy Publications.

Goldman, R. , \& Fristoe, M. (1986). Goldman-Fristoe test of articulation. Circle Pines, MN: American Guidance Service, Inc.

Halverson, C. \& \& Waldrop, M. (1970). Maternal behavior toward own and other preschool children: The problem of "ownness." Child Development, 41, 839-845.

Huttenlocher, J., Haight, W., Bryk, A., Seltzer, M., \& Lyons, T. (1991). Early vocabulary growth: Relation to language input and gender. Developmental Psychology, 27, 236-248.

Irwin, O., \& Chen, H. (1946). Development of speech during infancy: Curve of phonemic types. Journal of Experimental Psychology, 36, 431-436.

Kashani, J., Chapel, J., Ellis, J., \& Shekim, W. (1979). Hyperactive girls. Journal of Operational Psychiatry, 10, 145-148. 
Kirk, S., \& Gallagher, J. (1983). Educating exceptional children (4th ed.). Boston: Houghton Mifflin.

Lee, L. (1974). Developmental sentence analysis. Evanston, IL: Northwestern University Press.

Liss, M. (1981). Patterns of toy play: An analysis of sex differences. Sex Roles, 7 , 1143-1150.

Maccoby, E., \& Jacklin, C. (1974). The psychology of sex differences. Stanford, CA: Stanford University Press.

McCarthy, D. (1953). Some possible explanations of sex differences in language development and disorders. The Journal of Psychology, 35, 155-160.

Meyers, J. \& Bean, I. (1968). A decade later: A follow-up of social class and mental illness. New York: wiley \& Sons.

Moore, T. (1967). Language and intelligence: A longitudinal study of the first eight years. Human Development, 10, 88-106.

Morley, M. (1965). The development and disorders of speech in childhood. London: E. \& S. Livingstone Ltd.

Murray, A., Johnson, J., \& Peters, J. (1990). Finetuning of utterance length to preverbal infants: Effects on later language development. Journal of Child Language, 17, 511-525.

Naylor, H. (1980). Reading disability and lateral asymmetry: An information processing analysis. Psychological Bulletin, 87, 531-545.

O'Brien, M., \& Huston, A. (1985). Development of sextyped play behavior in toddlers. Developmental Psychology, 21. 866-871.

O'Brien, M. \& Nagle, K. (1987). Parents' speech to toddlers: The effect of play context. Journal of Child Language, 14, 269-279.

Paul, R. (1993). Patterns of development in late talkers: Preschool years. Journal of Childhood Communication Disorders, 15, 7-14.

Paul, R., \& Elwood, T. (1991). Maternal linguistic input to toddlers with slow expressive language development. Journal of Speech and Hearing Research, 34, 982-988. 
Phillips, J. (1973). Syntax and vocabulary of mothers' speech to young children: Age and sex comparison. Child Development, 44, 182-185.

Phipps, P. (1982). The LD learner is often a boy Why? Academic Therapy, 17, 425-430.

Rescorla, L. (1989). The language development survey: A screening tool for delayed language in toddlers. Journal of Speech \& Hearing Disorders, 54, 587-599.

Retherford, K., Schwartz, B., \& Chapman, R. (1981). Semantic roles and residual grammatical categories in mother and child speech: Who tunes into whom? Journal or Child Language, $\underline{8}$, 583-608.

Rosenthal, J. (1970). A preliminary psycholinguistic study of children with learning disabilities. Journal of Learning Disabilities. 3 , 391-395.

Ryckman, D. (1981). Sex differences in a sample of learning disabled children. Learning Disability ouarterly, 4, 48-52.

Satz, P., \& Zaide, J. (1983). Sex differences: Clues and myths on genetic aspects of speech and language disorders? In C. Ludlow \& J. Cooper (Eds.), Genetic aspects of speech and language disorders (pp. 97-102). Bethesda, MD: Academic Press.

Scarborough, H., \& Dobrich, W. (1990). Development of children with early language delay. Journal of speech and Hearing Research, 33, 70-83.

Schachter, F. (1979) . Everyday mother talk to toddlers: Early intervention. San Diego, CA: Academic Press.

Schodorf, J., \& Edwards, H. (1983). Comparative analysis of parent-child interactions with languagedisordered and linguistically normal children. Journal of Communication Disorders, 16, 71-83.

Shaywitz, S., Shaywitz, B., Fletcher, J., \& Escobar, M. (1990). Prevalence of reading disability in boys and girls. Journal of the American Medical Association, 264, 998-1002.

Shriberg, L., \& Kwiatkowski, J. (1988). A follow-up study of children with phonologic disorders of unknown origin. Journal of Speech and Hearing Disorders, 53, 144155 . 
Silva, P., Williams, S., \& McGee, R. (1987). A longitudinal study of children with developmental language delay at age three: Later intelligence, reading, and behavior problems. Developmental Medicine and Child Neurology, 29, 630-640.

Smolak, L. (1987). Child characteristics and maternal speech. Journal of Child Language, 14, 481-492.

Snow, c. (1972). Mothers' speech to children learning language. Child Development, 43, 549-565.

Templin, M. (1957). Certain language skills in children. Minneapolis, MN: The university of Minnesota Press.

Tiegerman, E., \& Siperstein, M. (1984). Individual patterns of interaction in the mother-child dyad:

Implications for parent intervention. Topics in language Disorders, 4, 50-61.

Tittemore, J., Lawson, J., \& Inglis, J. (1985). Validation of a learning disability index derived from a principal components analysis of the WISC-R. Journal of Learning Disabilities, 18, 449-454.

Vogel, S., \& Walsh, P. (1987). Gender differences in cognitive abilities in learning disabled females and males. Annals of Dyslexia, 37, 142-165.

Walker, D., Greenwood, C., Hart, B., \& Carta, J. (1994). Prediction of school outcomes based on early language production and socioeconomic factors. Child Development, 65, 606-621.

Weintraub, P. (1981). The brain: His and hers. Discover, $\underline{2}, 15-20$.

Whitehurst, G., Fischel, J., Lonigan, C., ValdezMenchaca, M., DeBaryshe, B., \& Caulfield, M. (1988). Verbal interaction in families of normal and expressivelanguage-delayed children. Developmental Psychology, 24, 690-699.

Whitehurst, G., Epstein, J., Angell, A., Payne, A., Crone, D., \& Fischel, J. (1994). Outcomes of an emergent literacy intervention in head start. Journal of Educational Psychology, 86, 542-555. 
Whitehurst, G., Fischel, J., Lonigan, C., ValdezMenchaca, M., Arnold, D., \& Smith, M. (1991). Treatment of early expressive language delay. Topics in Lanquage Disorders, 11, 55-68.

Wiig, E., \& Semel, E. (1984). Language assessment and intervention. Columbus, OH: Merrill.

Winitz, H. (1959). Language skills of male and female kindergarten children. Journal of Speech and Hearing Research, $\underline{2}, 377-386$.

witelson, S. (1976). Sex and the single hemisphere: Right hemisphere specialization for spatial processing. Science, $193,425-427$.

witelson, S. (1977). Developmental dyslexia: Two right hemispheres and none left. Science, 195, 309-311. 
APPENDIX A

HUMAN SUBJECTS RESEARCH WAIVER 


\section{OFFICE OF GRADUATE STUDIES AND RESEARCH}

Research and Sponsored Projects

DATE: October 23, 1995

$\begin{array}{ll}\text { TO: } & \text { Nancy A. Johnson SSN\# 543-72-9151 } \\ \text { FROM: Laurie Skokan, Chair, HSRRC, 1995-96 } & \begin{array}{l}\text { HSRRC Waived Review of Your Application titled "Gender Differences in the } \\ \text { Development of Expressive Language in Late-Talking 3-Year-Old Toddlers" }\end{array}\end{array}$

Your proposal is exempt from further HSRRC review, and you may proceed with the study.

Even with the exemption above, it was necessary by University policy for you to notify this Committee of the Proposed research and we appreciate your timely attention to this matter. If you make changes in your research protocol, the Committee must be notified. This approval is valid for one year from date of issue.

c: $\quad$ Maureen Orr Eldred

Rhea Paul. Project Advisor

waiver.mem 


\section{APPENDIX B}

\section{LANGUAGE DEVELOPMENT SURVEY}

Rescorla, L. (1989). The Language Development Survey: A screening tool for delayed language in toddlers.

Journal of Speech and Hearing Disorders, 54, 587-599. 


\section{Language Development Survey}

The Language Development Survey is designed to measure vocabulary development and early word combinations in young children by the use of parent report. By carefully completing the Languagc Devclonment Survcy, you can help us obiain an accuratc picturc of your child's developing languagc skills. Plcase check off each word your child says. Don't include words your child understands but ducs not say. It's all right to count words that arcn't pronounced clcarly. Don't count words which your child repcats alter you in imitation but docs not say spontancously

Thank you for helping us icarn morc abuut your child's language development.

Dale 111 Yourname

Child's name

Scx

Mothcr's namc

Addiess

Telephione

Datc of birth

Marital status

Level of cducation completcd

Employment:

Not cmployed

Employed part-timc

Employed full-time

Occupation
Birthdatc 11

Age

Fathcr's namc

Address

Tclephonc

Datc of birth

Marital status

Level of education completed

Employment:

Not employed

Employed part-time

Employed full-time

Occupation

Plcase give age and scx of othcr children in your family

Has anyonc in your family becn slow in lcarning to talk?

If so, who?

Was your child premature?

How many weeks early?

How many car infections has your child had?

Is your child in day carc or carcd for regularly by a babysittcr?

If so, how many hours per wcck?

What language is snoken in your home?

Plcasc list languages spoken if other than English

Are you worried about your child's language development?

PLEASE COMPLETE VOCABULARY CHECKLIST ON REVERSE SIDE

OLesile Rescorla. Ph.D 


\section{Language Development Survey}

Plcasc check off cach word that your child says SPONTANEOUSLY (not just imitates or understands). li's okay to count words that aren't pronounced clearly or arc in "baby talk" ("baba" for bottlc.)

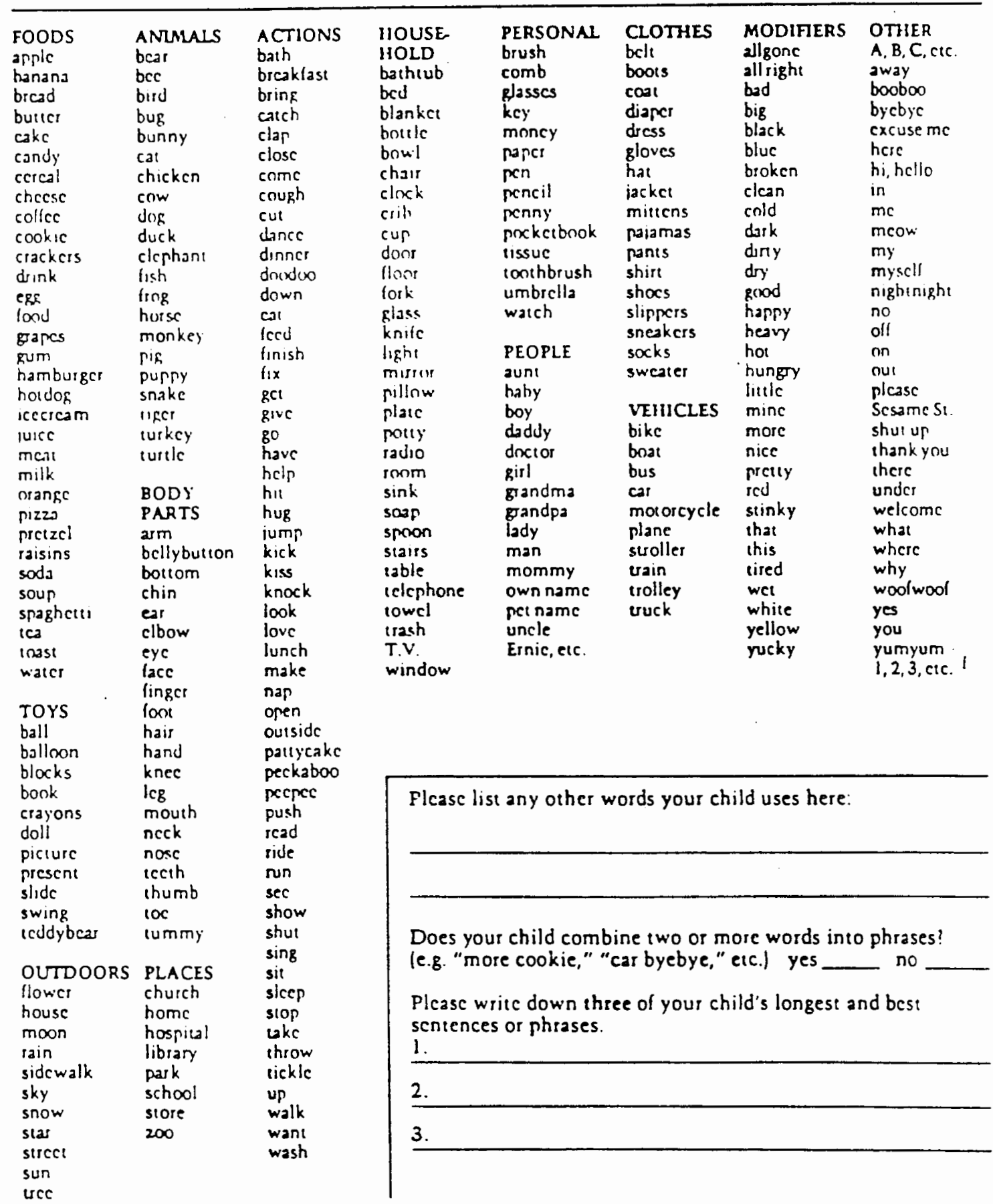


APPENDIX C

RAW DATA FOR THE TWO GROUPS OF SUBJECTS

AT INTAKE AND 3-YEAR EVALUATION 
BOYS' RAW DATA AT INTAKE AND 3-YEAR EVALUATION

\begin{tabular}{|c|c|c|c|c|c|c|c|c|c|}
\hline \multirow{2}{*}{ Subject } & \multicolumn{3}{|c|}{ Intake Information } & \multicolumn{6}{|c|}{ 3-Year-old Evaluation Scores } \\
\hline & $\begin{array}{l}\text { Age } \\
\text { Mos. }\end{array}$ & SES & LDS & $\begin{array}{l}\text { Age } \\
\text { Mos. }\end{array}$ & $\begin{array}{c}\text { EOWPVT } \\
\text { standard }\end{array}$ & $\begin{array}{l}\text { GFTA } \\
\text { sile }\end{array}$ & $\begin{array}{c}\text { TACL-R } \\
\text { Standard }\end{array}$ & $\begin{array}{c}\text { PPVT } \\
\text { standard }\end{array}$ & $\begin{array}{l}\text { DSS } \\
\text { Raw }\end{array}$ \\
\hline 006 & 23 & 4 & 08 & 36 & 103 & 41 & 069 & 094 & 3.74 \\
\hline 007 & 23 & 4 & 09 & 36 & 099 & 30 & 085 & 106 & 2.82 \\
\hline 053 & 28 & 3 & 30 & 40 & 108 & 02 & 102 & 105 & 6.12 \\
\hline 084 & 23 & 4 & 37 & 37 & 134 & 25 & 113 & 125 & 5.00 \\
\hline 085 & 28 & 3 & 19 & 37 & 093 & 05 & 082 & 092 & 4.00 \\
\hline 087 & 25 & 3 & 05 & 37 & 115 & 37 & 098 & 118 & 2.36 \\
\hline 090 & 28 & 3 & 06 & 39 & 091 & 04 & 082 & 104 & 0.00 \\
\hline 091 & 27 & 4 & 16 & 39 & 084 & 01 & 096 & 108 & 0.00 \\
\hline 092 & 33 & 4 & 45 & 43 & 108 & 09 & 125 & 110 & 5.56 \\
\hline 093 & 24 & 3 & 22 & 37 & 071 & 10 & 069 & 063 & 0.00 \\
\hline 094 & 31 & 3 & 23 & 40 & 055 & 01 & 104 & 103 & 0.00 \\
\hline 097 & 22 & 3 & 12 & 37 & 108 & 28 & 099 & 115 & 2.21 \\
\hline 098 & 21 & 4 & 45 & 37 & 108 & 14 & 105 & 106 & 5.23 \\
\hline 100 & 29 & 5 & 27 & 36 & 086 & 03 & 110 & 094 & 0.00 \\
\hline 103 & 25 & 4 & 15 & 36 & 103 & 06 & 107 & 110 & 0.00 \\
\hline 105 & 24 & 2 & 07 & 37 & 124 & 22 & 106 & 117 & 4.80 \\
\hline 107 & 22 & 4 & 06 & 35 & 097 & 62 & 102 & 095 & 4.08 \\
\hline 112 & 27 & 2 & 35 & 38 & 095 & 03 & 101 & 107 & 0.00 \\
\hline 114 & 24 & 4 & 07 & 36 & 108 & 07 & 105 & 098 & 2.05 \\
\hline 115 & 29 & 3 & 06 & 44 & 090 & 19 & 075 & 077 & 2.81 \\
\hline 116 & 31 & 2 & 29 & 41 & 083 & 22 & 074 & 064 & 0.00 \\
\hline 119 & 26 & 4 & 02 & 36 & 120 & 07 & 104 & 119 & 4.66 \\
\hline 211 & 26 & 3 & 03 & 36 & 055 & 01 & 069 & 040 & 0.00 \\
\hline
\end{tabular}


GIRLS' RAW DATA AT INTAKE AND 3-YEAR EVALUATION

\begin{tabular}{|c|c|c|c|c|c|c|c|c|c|}
\hline \multirow{2}{*}{ subject } & \multicolumn{3}{|c|}{ Intake Information } & \multicolumn{6}{|c|}{ 3-Year-old Evaluation Scores } \\
\hline & $\begin{array}{l}\text { Age } \\
\text { Mos. }\end{array}$ & SES & LDS & $\begin{array}{l}\text { Age } \\
\text { Mos. }\end{array}$ & $\begin{array}{c}\text { EOWPVT } \\
\text { standard }\end{array}$ & $\begin{array}{l}\text { GFTA } \\
\text { gile }\end{array}$ & $\begin{array}{c}\text { TACL-R } \\
\text { Standard }\end{array}$ & $\begin{array}{c}\text { PPVT } \\
\text { Standard }\end{array}$ & $\begin{array}{l}\text { DSS } \\
\text { Raw }\end{array}$ \\
\hline 012 & 22 & 5 & 44 & 36 & 110 & 01 & 111 & 103 & 2.68 \\
\hline 029 & 26 & 5 & 14 & 38 & 082 & 10 & 099 & 089 & 0.00 \\
\hline 052 & 22 & 3 & 36 & 37 & 055 & 01 & 080 & 075 & 2.04 \\
\hline 057 & 24 & 2 & 20 & 41 & 098 & 14 & 104 & 094 & 4.97 \\
\hline 111 & 24 & 3 & 13 & 39 & 089 & 01 & 096 & 111 & 3.78 \\
\hline 142 & 22 & 4 & 05 & 37 & 091 & 15 & 103 & 103 & 7.02 \\
\hline 200 & 25 & 4 & 05 & 36 & 055 & 01 & 105 & 075 & 0.00 \\
\hline 202 & 31 & 3 & 24 & 38 & 055 & 01 & 082 & 088 & 0.00 \\
\hline 213 & 27 & 3 & 14 & 37 & 107 & 85 & 101 & 092 & 6.78 \\
\hline 214 & 26 & 3 & 38 & 36 & 088 & 01 & 114 & 113 & 0.00 \\
\hline 215 & 25 & 3 & 36 & 37 & 118 & 02 & 113 & 108 & 0.00 \\
\hline 217 & 27 & 3 & 44 & 38 & 095 & 03 & 097 & 097 & 0.00 \\
\hline 219 & 27 & 3 & 08 & 36 & 055 & 01 & 106 & 109 & 0.00 \\
\hline 220 & 28 & 3 & 11 & 36 & 055 & 01 & 069 & 075 & 0.00 \\
\hline 221 & 32 & 1 & 35 & 37 & 084 & 01 & 075 & 054 & 0.00 \\
\hline 222 & 28 & 4 & 00 & 36 & 055 & 01 & 080 & 044 & 0.00 \\
\hline
\end{tabular}

